\title{
Monitoring the Short-Term Response to Salt Exposure of Two Genetically Distinct Phragmites australis Clones with Different Salinity Tolerance Levels
}

\author{
Luciana Achenbach*, Hans Brix \\ Department of Bioscience, Section of Aquatic Biology Aarhus University, Aarhus, Denmark \\ Email: "luciana.achenbach@gmail.com
}

Received 20 January 2014; revised 24 February 2014; accepted 11 March 2014

Copyright (C) 2014 by authors and Scientific Research Publishing Inc.

This work is licensed under the Creative Commons Attribution International License (CC BY). http://creativecommons.org/licenses/by/4.0/

(c) (i) Open Access

\begin{abstract}
Aims: Two genetically distinct clones of Phragmites australis were used to investigate the immediate response induced by osmotic stress. The study aimed at elucidating if the response time, the inhibition rate and the recovery from salinity stress vary between these two genotypes. The experimental work was conducted at the laboratory of the Institute of Bioscience, Aarhus University, Denmark. Methods: The light-saturated photosynthetic rate $\left(P_{\max }\right)$, stomata conductance $\left(g_{s}\right)$ and transpiration rate $(E)$ were measured over different periods of salt exposure $(15,70$ and 240 minutes) and at different salt concentrations (20 and 40 parts per thousand salinity). Important findings: The osmotic stress induced stomata closure and reduction of $P_{\max }$ and $E$ for both clones. The clone-specific responses as measured through physiological parameters were negatively correlated with exposure time and salt concentration. During the 4-hour exposure at $20 \mathrm{ppt}$, the two clones were inhibited at different rates. The salt-sensitive Land-type showed an immediate reduction of $P_{\max }, g_{s}$ and $E$. No recovery was observed after removing the salt solution. At the same salt concentration, the reduction of $P_{\max } g_{s}$ and $E$ of the Greeny-type was lower and immediate recovery was observed when the root zone was rinsed. Both clones were irreversibly inhibited after 4 hours of exposure to $40 \mathrm{ppt}$. Recovery was primarily related to exposure time, as $P_{\max }, g_{s}$ and $E$ rates of both clones recovered completely after fresh-water rinsing in the 15-minute experiment. The Greeny-type also recovered after the 70-minute exposure, but not the Land-type. We conclude that the response to osmotic stress is genotype-dependent and that the salt-tolerant clone possesses very efficient signaling pathways to detect changes in the soil water potential and adjust accordingly.
\end{abstract}

${ }^{*}$ Corresponding author.

How to cite this paper: Achenbach, L. and Brix, H. (2014) Monitoring the Short-Term Response to Salt Exposure of Two Genetically Distinct Phragmites australis Clones with Different Salinity Tolerance Levels. American Journal of Plant Sciences, 5, 1098-1109. http://dx.doi.org/10.4236/ajps.2014.58122 


\section{Keywords}

\section{Osmotic Stress; Salt Stress Response; Photosynthesis; Common Reed}

\section{Introduction}

The wetland grass Phragmites australis is one of the most widely spread species in the temperate region [1], and can be found on all continents except Antarctica. Its cosmopolitan distribution is supported by the clonal reproduction, but also by the high genetic variability within the species, as distinct populations often co-exist and cross-pollinate [2]. The morphological and physiological traits of genetically distinct P. australis clones vary widely [3]-[7], and various $P$. australis ecotypes have evolved resistance to different types of environmental stress, such as drought, salinity or low temperature [8]-[13]. This may be the key reason why populations of common reed are, in some parts of the world, a component of balanced and diverse wetland ecosystems, while in others Phragmites australis is highly undesired and classified as a weed.

Expanding population of $P$. australis have been reported on the East Coast of the United States, where introduced invasive genotypes from Europe are out-competing the natively occurring vegetation [14] [15]. Among possible features of successful invaders, a broader environmental niche, vigorous hybrids or higher tolerance range have been suggested [16] and investigated for different $P$. australis genotypes [13] [15] [17].

Various introduced $P$. australis genotypes are competing in the Gulf Coast of the US-a "hot-spot” of $P$. australis genetic diversity. Very interesting dynamics of introduced $P$. australis populations can be observed in the Mississippi River Delta. According to Hauber et al. [17], several introductions have occurred; hence, the genotypes interacting in the area have different origins and gene pools. Lambertini et al. [18] have identified four different phenotypes. Their distribution seems to be correlated to a salinity gradient, as certain phenotypes are found predominantly in the outer and salt-affected marshes, whereas others are prevalently spread inland (Landtype). The most productive strains (EU- and Delta-type) are located in the brackish lowlands and their higher salinity tolerance compared to the Land-type has been proven by Achenbach and Brix [19]. It is apparent that the ability of certain $P$. australis genotypes to cope with salt stress plays a crucial role in their observed colonizing of coastal habitats, usually in the disfavor of less salt tolerant genotypes/species.

The salinity tolerance range of individual $P$. australis genotypes has previously been reported to vary significantly [19]-[23]. While for most populations the growing optimum lies between 0 and 16 ppt [10] [20], several genotypes have a salinity tolerance reaching $30 \mathrm{ppt}$ [19] [21] [23]. Furthermore, progressive exposure studies [20] have revealed that under acclimation, certain P. australis genotypes can still survive at 56 ppt. Different response mechanisms were found, such as reduced water uptake through closed stomata, $\mathrm{Na}^{+}$exclusion through selective channels at the root level, or compartmentalization of $\mathrm{Na}^{+}$into the vacuoles [19] [20]. However, the physiological processes associated with salt-stress response are complex, and dependent on several variables, such as salt concentration or exposure time [24].

Mechanisms of salinity tolerance involve a rapid, osmotic response, and a slower, ionic response [24]. The osmotic response is triggered by the low water potential of the salt solution. The osmotic stress immediately reduces cell turgor in root tips and young leaves, and causes stomata closure. Consequently, it may determine a down-regulation of the transpiration stream. This impedes the uptake of toxic solutes, but it also reduces growth. Previous results have shown that certain genotypes of $P$. australis are able to sustain high $P_{\text {max }}$ despite partial stomata closure [19]. Thus, carbon fixation continues and water use efficiency increases. This process is, however, associated to low salinities up to $10 \mathrm{ppt}$ [19] [24], under long-term exposure, as the uptake of toxic ions eventually induces ionic stress and severe inhibition of photosynthesis [20].

In this study, we compare the short-term response to salinity of a salt-sensitive clone (Land-type) and a salttolerant clone (Greeny-type) from the Mississippi River Delta. The question that we try to answer is how fast $P$. australis can sense a change in soil water potential when fresh water in the soil is replaced by salt solutions of different concentrations. We hypothesize that the response to a sudden increase in salinity in the rhizosphere is dependent on the genetic background of the plants, as salt-tolerant clones are less inhibited and better adjusted to changes in the soil water potential.

Our aims are to 1) test if the response time to sense and regulate osmotic stress varies between genotypes, 2) 
assess the maximum salt concentration where the damage is reversible for each genotype and 3) ascertain to which extent plants can regain functionality after different salt-stress exposure periods.

\section{Materials and Methods}

\subsection{Plant Material}

Based on previous results [19], two clones of P. australis from the Mississippi River Delta with different salinity tolerance levels were selected. The Greeny-type was shown to tolerate salinities as high as $40 \mathrm{ppt}$, whereas the Land-type was strongly inhibited at salt concentrations higher than $20 \mathrm{ppt}$.

In order to produce similar-sized genetically identical plants for use in the experiment, harvested shoots of the two different $P$. australis clones were placed horizontally on a sand substrate with $2-3 \mathrm{~cm}$ water layer, in a heated greenhouse $\left(20^{\circ} \mathrm{C}\right)$ for one month, until new adventitious shoots with roots were produced at the stem nodes of the layered shoots. Five genetically identical shoots of each clone were then separated and similar-sized plants were distributed in $3.5 \mathrm{~L}$ plastic pots (top diameter $18 \mathrm{~cm}$, bottom diameter $13 \mathrm{~cm}$, height $17.5 \mathrm{~cm}$ ). The pots were filled with sand and watered every second day with a fertilizing solution prepared from tap water and commercial nutrient solutions (100 mg. $\mathrm{L}^{-1}$ Pioner NPK Makro 19-2-15 + Mg, Brøste, Lyngby, Denmark; 0.1 $\mathrm{ml} \cdot \mathrm{L}^{-1}$ Pioner Mikro plus with iron, Brøste, Lyngby, Denmark).

\subsection{Experimental Setup and Environmental Conditions}

The plants were kept in a growth chamber, which was set to $16 / 8 \mathrm{~h}$ light/dark cycle, at a temperature of $25^{\circ} \mathrm{C} /$ $22^{\circ} \mathrm{C}$ and $\mathrm{RH}$ of $60 \% / 70 \%$ respectively. The acclimation time before measurements started was 25 days. The light intensity (PAR) measured inside the growth chamber ranged from around $1200 \mu \mathrm{mol} \cdot \mathrm{m}^{-2} \mathrm{~s}^{-1}$ at the top, closest to the light source, to around $700 \mu \mathrm{mol} \cdot \mathrm{m}^{-2} \mathrm{~s}^{-1}$ at the height of the third fully-developed leaf ( $60 \mathrm{~cm}$ for the Land-type and $55 \mathrm{~cm}$ from the soil level for the Greeny-type).

Saturated water level was maintained by placing the pots with the plants in black $6 \mathrm{~L}$ buckets (top diameter $21.5 \mathrm{~cm}$, bottom diameter $16 \mathrm{~cm}$, height $20 \mathrm{~cm}$ ) which were filled to a height of approx. $10 \mathrm{~cm}$ with the fertilizing solution.

\subsection{Gas-Exchange Measurements}

The light-saturated rates of photosynthesis $\left(P_{\max }\right)$, transpiration $(E)$ and stomata conductance $\left(g_{s}\right)$ were measured on the third fully-developed leaf of each plant, using an Infrared Gas-Exchange Analyzer (LI-6400XT Portable Photosynthesis System, Li-Cor Biosciences, Lincoln, NE, USA). The leaf chamber was placed on a tripod to ensure stability during readings. Light was supplied by a 6400-02B LED light source (Li-Cor Biosciences, Lincoln, NE, USA) set at $1800 \mu \mathrm{mol} \cdot \mathrm{m}^{-2} \mathrm{~s}^{-1}$ irradiance. The temperature inside the leaf chamber was conditioned at $20^{\circ} \mathrm{C}$. Ambient $\mathrm{CO}_{2}$ was provided from the outside air through a tube, its concentration being rather constant.

The two clones were measured for three different target exposure times. First, a 4-hour exposure to salinity was performed, and the response to different salt concentrations (20 ppt and $40 \mathrm{ppt}$ ) was tested. Second, the exposure time was reduced to 15 minutes under $20 \mathrm{ppt}$ salt concentration. Third, the two clones were exposed to $20 \mathrm{ppt}$ for 70 minutes. Each experimental part was repeated three times.

In the 4-hour experiment, four distinct replicates of each clone were used in order to measure and compare the response of the third fully-developed leaf in four different stress situations: 1) leaf sectioning from the shoot, 2) shoot sectioning from the plant, 3) continuous exposure of the root system to 20 ppt salt stress and 4) continuous exposure of the root system to 40 ppt salt stress. In all four scenarios, measurements began one hour after the light in the growth chamber had automatically turned on, the plants being first measured for 60 - 65 minutes in unstressed conditions.

The first procedure consisted of recording the changes in $P_{\max }, g_{s}$ and $E$ when the third fully-developed leaf measured was cut from the shoot. In the second one, the measured shoot (of distinct replicates) was cut from the plant. These procedures were performed in order to compare the adjustment time of the two clones and also to test clone-specific stomata closure under severe dehydration, as water would no longer be provided to the measured leaf. The cutting was performed 60 minutes after the measurement start and readings were recorded every 30 seconds for 4 hours. The measured leaves were situated at a height of 60 to $70 \mathrm{~cm}$ (Land-type) and 55 to 63 cm (Greeny-type) as measured from the soil level. 
In the last two scenarios, salt solutions of 20 and 40 ppt concentration were administered to the root system of distinct unstressed replicates. The third fully-developed leaf was measured in stable conditions for about 60 - 65 minutes, after which the salt solution was added. Measurements continued for around 240 minutes, by which time all parameters had either stabilized again at lower values, or had reached zero. Afterwards, the salt solution was carefully drained from the outer bucket and then the plant root systems were rinsed with fresh water. In order to ensure that the salt in the soil had been completely removed, the water that had completely flushed the root system was drained and the procedure of rinsing with fresh water was repeated after approximately 5 - 10 minutes. The measurements continued for another 60 - 70 minutes, or, if signs of recovery were present, up to 120 minutes. The same plants were shortly (3 minutes) measured again after three days in fresh water, to check for full recovery.

The second and third experiment targeted transitory short-term exposure to $20 \mathrm{ppt}$ salinity, with the salt stress being removed after 15 minutes and after 70 minutes respectively. As the number of available replicates was limited, previously salt-exposed plants (also to $20 \mathrm{ppt}$ ) were used for these shorter time periods. However, these plants were allowed one week to recover. Hence, a newly grown third fully-developed leaf was measured. Similar to the 4-hour experiment, the measurements started under stable conditions (without salinity) for 20 minutes and 40 minutes respectively prior to treatment administration. The physiological parameters were monitored up to 80 minutes after rinsing the rhizosphere with fresh water.

\section{Results and Discussions}

\subsection{Measuring the Response Time}

The response of the plants after cutting the third fully-developed leaf consisted of an immediate reduction of the net $\mathrm{CO}_{2}$ assimilation rate (Figures $\mathbf{1}(\mathrm{A})$ and $(\mathrm{B})$ green curve), reaching values close to zero within minutes. The same pattern was observed for stomata conductance and transpiration (Figures 2 and 3 green curve).

Similar results were recorded when the entire shoot was cut (Figures 1-3 black curve). The reduction in $P_{\max }$, $\mathrm{g}_{\mathrm{s}}$ and $E$ was equally fast to the leaf-cut, but slowed down in the lower range $\left(P_{\max }\right.$ under $\left.5 \mu \mathrm{mol} \cdot \mathrm{m}^{-2} \mathrm{~s}^{-1}\right)$, reaching zero in around 60 minutes after the damage had occurred (Figure 1). The pattern was identical for both clones, thus the "reaction time" was estimated to be equal.

\subsection{4-Hour Exposure at 20 ppt}

Administering a salt solution of 20 ppt concentration resulted in different responses of the two clones. The $P_{\max }$, $g_{s}$ and $E$ were strongly reduced (Figures 1-3 yellow curve) for both clones. Yet, in the case of the Greeny-type, $P_{\max }$ stabilized at around $8 \mu \mathrm{mol} \cdot \mathrm{m}^{-2} \mathrm{~s}^{-1}$ (Figure 1(A)) after around 120 minutes of salt exposure and stayed stable for the remaining time of the experiment (approximately another 100 minutes). The $P_{\max }$ values for the Land-type were reduced from $40 \mu \mathrm{mol} \cdot \mathrm{m}^{-2} \mathrm{~s}^{-1}$ to $20 \mu \mathrm{mol} \cdot \mathrm{m}^{-2} \mathrm{~s}^{-1}$ within 5 minutes (Figure 1(B) yellow curve). After an attempt of stabilizing at $20 \mu \mathrm{mol} \cdot \mathrm{m}^{-2} \mathrm{~s}^{-1}$ for about 5 minutes, the $P_{\max }$ further declined to $0 \mu \mathrm{mol} \cdot \mathrm{m}^{-2} \mathrm{~s}^{-1}$ within around 40 minutes.

The inhibition of $g_{s}$ and $\mathrm{E}$ also differed between the two clones. For the Greeny-type, a sudden decrease in the first 10 minutes of salt stress was measured, but $g_{s}$ and $E$ stabilized at $0.5 \mathrm{~mol} \cdot \mathrm{m}^{-2} \mathrm{~s}^{-1}$ and $7 \mathrm{~mol} \cdot \mathrm{m}^{-2} \mathrm{~s}^{-1}$ respectively for a short period of time. A smooth decline was recorded in the next 200 minutes, with the minimum values reaching $0.1 \mathrm{~mol} \cdot \mathrm{m}^{-2} \mathrm{~s}^{-1}$ and $1 \mathrm{mmol} \cdot \mathrm{m}^{-2} \mathrm{~s}^{-1}$, respectively (Figures 2(A) and 3(A) yellow curve). On the other hand, in the case of the Land-type, the $g_{s}$ values steeply decreased from $1 \mathrm{~mol} \cdot \mathrm{m}^{-2} \mathrm{~s}^{-1}$ to $0.1 \mathrm{~mol} \cdot \mathrm{m}^{-2} \mathrm{~s}^{-1}$ and the $E$ values from $8 \mathrm{mmol} \cdot \mathrm{m}^{-2} \mathrm{~s}^{-1}$ to $1 \mathrm{mmol} \cdot \mathrm{m}^{-2} \mathrm{~s}^{-1}$ within minutes after administering the salt solution. The $g_{s}$ and $E$ stabilized at these values for around 10 minutes, and then continued to decrease, reaching full inhibition after 30 minutes of salt stress (Figures 2(B) and 3(B) yellow curve).

\subsection{4-Hour Exposure at 40 ppt}

Different unstressed replicates of the two clones were exposed to a salt concentration of $40 \mathrm{ppt}$. Both clones registered a steep decline of $P_{\max }, g_{s}$ and $E$ (Figures 1-3 red curve). However, while the physiological parameters of the Land-type were inhibited to zero within 10 minutes after salt administration, in the case of the Greenytype, stable values were measured after approximately five minutes of exposure, but only for 5 - 7 minutes (Figures 1(A), 2(A) and 3(A)). The initial decrease was from $32 \mu \mathrm{mol} \cdot \mathrm{m}^{-2} \mathrm{~s}^{-1}$ to $12 \mu \mathrm{mol} \cdot \mathrm{m}^{-2} \mathrm{~s}^{-1}$ for $P_{\max }$, from 


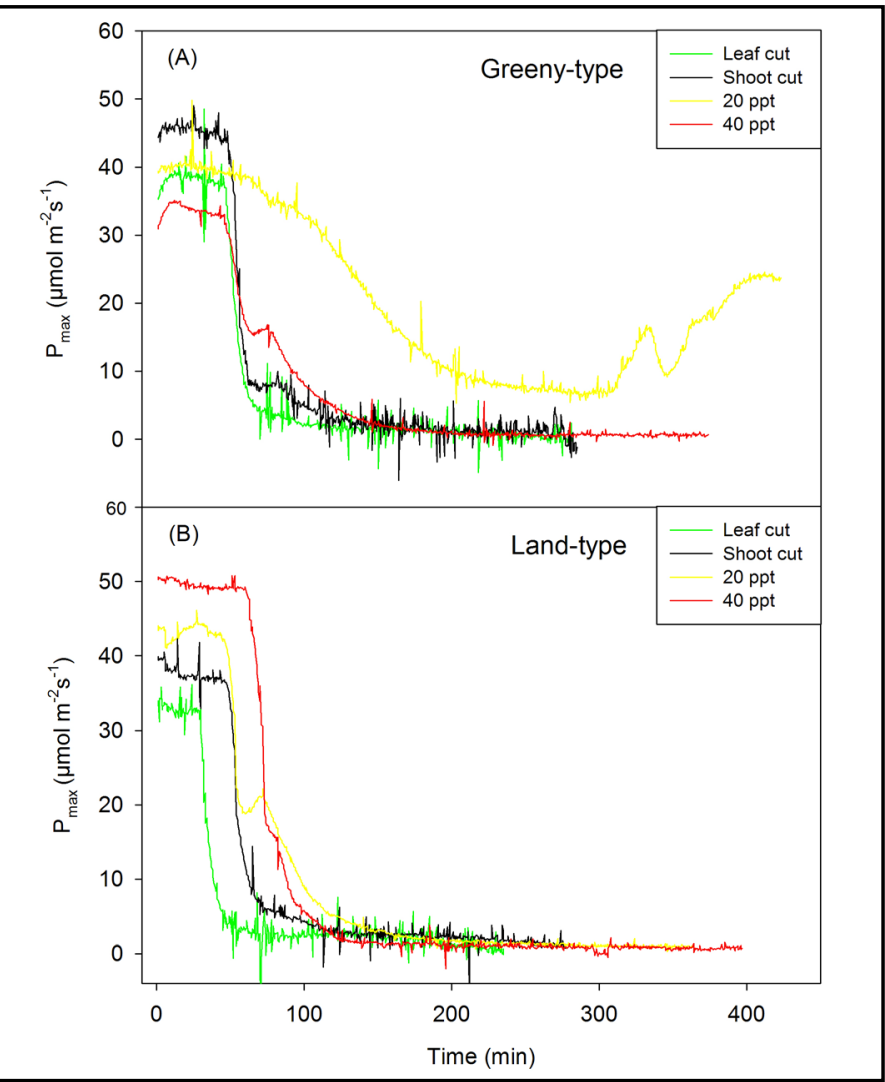

Figure 1. The response of the light-saturated rate of photosynthesis $\left(P_{\max }\right)$ of two different $P$. australis clones to leaf cut, shoot cut, and administering 20 and 40 ppt salt concentration for 4 hours.

$0.5 \mathrm{~mol} \cdot \mathrm{m}^{-2} \mathrm{~s}^{-1}$ to $0.1 \mathrm{~mol} \cdot \mathrm{m}^{-2} \mathrm{~s}^{-1}$ for $g_{\mathrm{s}}$ and from $7 \mathrm{mmol} \cdot \mathrm{m}^{-2} \mathrm{~s}^{-1}$ to $2 \mathrm{mmol} \cdot \mathrm{m}^{-2} \mathrm{~s}^{-1}$ for $E$. The stable values were followed by a smoother decrease, reaching zero after 30 minutes of salt stress.

\subsection{Recovery}

The recovery process was not only genotype-dependent, but also strongly correlated both to the salt concentration and to the exposure time. While the Land-type showed no immediate recovery after 4 hours of exposure to $20 \mathrm{ppt}$, the Greeny-type exposed to the same salt concentration for the same period of time recovered partially within minutes after rinsing the root zone with fresh water (Figures 1(A), 2(A) and 3(A) yellow curve). The high responsiveness of this clone to changes in soil water potential is further supported by a second short time decrease in $P_{\max }, g_{s}$ and $E$ associated to the second draining of the water (approximately 350 minutes from the beginning of the experiment), and the immediate increase as soon as new fresh water was administered (Figures 1(A), 2(A) and 3(A) yellow curve).

None of the two clones showed immediate recovery signs when rinsed with fresh water after the 4-hour exposure to $40 \mathrm{ppt}$. However, after three days, $P_{\max }$ had recovered to $21 \mu \mathrm{mol} \cdot \mathrm{m}^{-2} \mathrm{~s}^{-1}$ for the Greeny-type and 10 $\mu \mathrm{mol} \cdot \mathrm{m}^{-2} \mathrm{~s}^{-1}$ for the Land-type (compared to $32 \mu \mathrm{mol} \cdot \mathrm{m}^{-2} \mathrm{~s}^{-1}$ and $48 \mu \mathrm{mol} \cdot \mathrm{m}^{-2} \mathrm{~s}^{-1}$, initial values of Greeny- and Land-type, respectively).

\subsection{Transitory Exposure (15 and 70 Minutes) at 20 ppt}

As both clones were sensitive to $20 \mathrm{ppt}$ salinity, with the possibility of recovery, the exposure time under this salt concentration was reduced to 15 and 70 minutes. Measurements of $P_{\max }, g_{s}$ and $E$ were performed on the two clones. The results were rather surprising, since the inhibition measured this time was lower, compared to the previous response. 


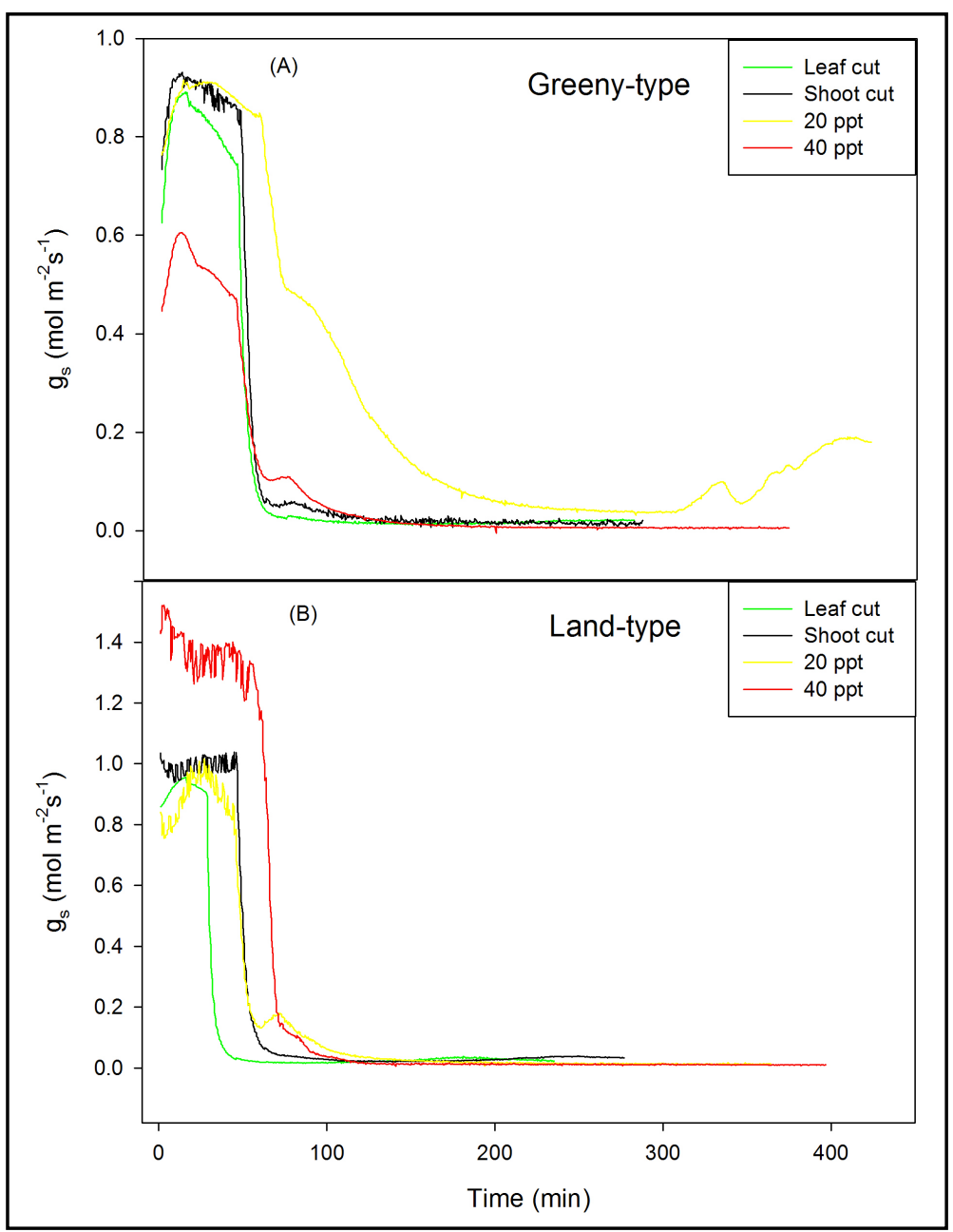

Figure 2. The response of stomata conductance $\left(g_{s}\right)$ of two different $P$. australis clones to leaf cut, shoot cut, and administering 20 and 40 ppt salt concentration for 4 hours.

In the 15 minutes salt exposure, the response of the two clones was very different, yet in both cases, recovery was observed after salt removal. For the Greeny-type, despite rather high fluctuations, a slight increase in $P_{\max }$ after salt administration was recorded (Figure 4(A)). The $\mathrm{g}_{\mathrm{s}}$ was only minimaly inhibited from $0.49 \mathrm{~mol} \cdot \mathrm{m}^{-2} \mathrm{~s}^{-1}$ to $0.43 \mathrm{~mol} \cdot \mathrm{m}^{-2} \mathrm{~s}^{-1}$ and $\mathrm{E}$ from $7.4 \mathrm{mmol} \cdot \mathrm{m}^{-2} \mathrm{~s}^{-1}$ to $6.8 \mathrm{mmol} \cdot \mathrm{m}^{-2} \mathrm{~s}^{-1}$. These values were hardly detectable at the scale of the previous inhibition range (the 4-hour experiment) and all parameters quickly returned to the initial values after rinsing. The $P_{\max }$ of the Land-type was reduced from $27 \mu \mathrm{mol} \cdot \mathrm{m}^{-2} \mathrm{~s}^{-1}$ to $23 \mu \mathrm{mol} \cdot \mathrm{m}^{-2} \mathrm{~s}^{-1}$ and recovered immediately after the root zone was rinsed with fresh water. For the same clone, $g_{s}$ decreased from $0.36 \mathrm{~mol} \cdot \mathrm{m}^{-2} \mathrm{~s}^{-1}$ to $0.23 \mathrm{~mol} \cdot \mathrm{m}^{-2} \mathrm{~s}^{-1}$ and increased back to the initial values after rinsing, while E decreased from $5.2 \mathrm{mmol} \cdot \mathrm{m}^{-2} \mathrm{~s}^{-1}$ to $4 \mathrm{mmol} \cdot \mathrm{m}^{-2} \mathrm{~s}^{-1}$, and increased to $5.4 \mathrm{mmol} \cdot \mathrm{m}^{-2} \mathrm{~s}^{-1}$ after rinsing (Figures $4(D)-(F)$ ).

In the 70 minutes salt exposure, the response of the two clones was again very different. The Greeny-type had a small decrease in $P_{\max }$ (from $29 \mu \mathrm{mol} \cdot \mathrm{m}^{-2} \mathrm{~s}^{-1}$ to $25 \mu \mathrm{mol} \cdot \mathrm{m}^{-2} \mathrm{~s}^{-1}$ ), and recovered well after rinsing (Figure 5(A)). Small reductions of $g_{s}$ (from $0.4 \mathrm{~mol} \cdot \mathrm{m}^{-2} \mathrm{~s}^{-1}$ to $0.3 \mathrm{~mol} \cdot \mathrm{m}^{-2} \mathrm{~s}^{-1}$ ) and $E$ (from $7 \mathrm{mmol} \cdot \mathrm{m}^{-2} \mathrm{~s}^{-1}$ to $5.5 \mathrm{mmol} \cdot \mathrm{m}^{-2} \mathrm{~s}^{-1}$ ) were also measured (Figures 5(B) and (C)). After rinsing the root zone of the Greeny-type with fresh water, $g_{s}$ and $E$ recovered and stabilized at the exact values as before the stress period.

For the Land-type, an inhibition of $10 \%-15 \%$ of the initial values was measured for $P_{\max }, g_{s}$ and $E$ shortly after administering the salt solution. The $P_{\max }$ stayed stable during the 70 minutes of salt stress, but did not recover at all after rinsing the rhizosphere and continued to decrease even after one hour of fresh water exposure. The $g_{s}$ and $E$ of the Land-type were also stable during the 70 minutes salt exposure, and even increased slightly 


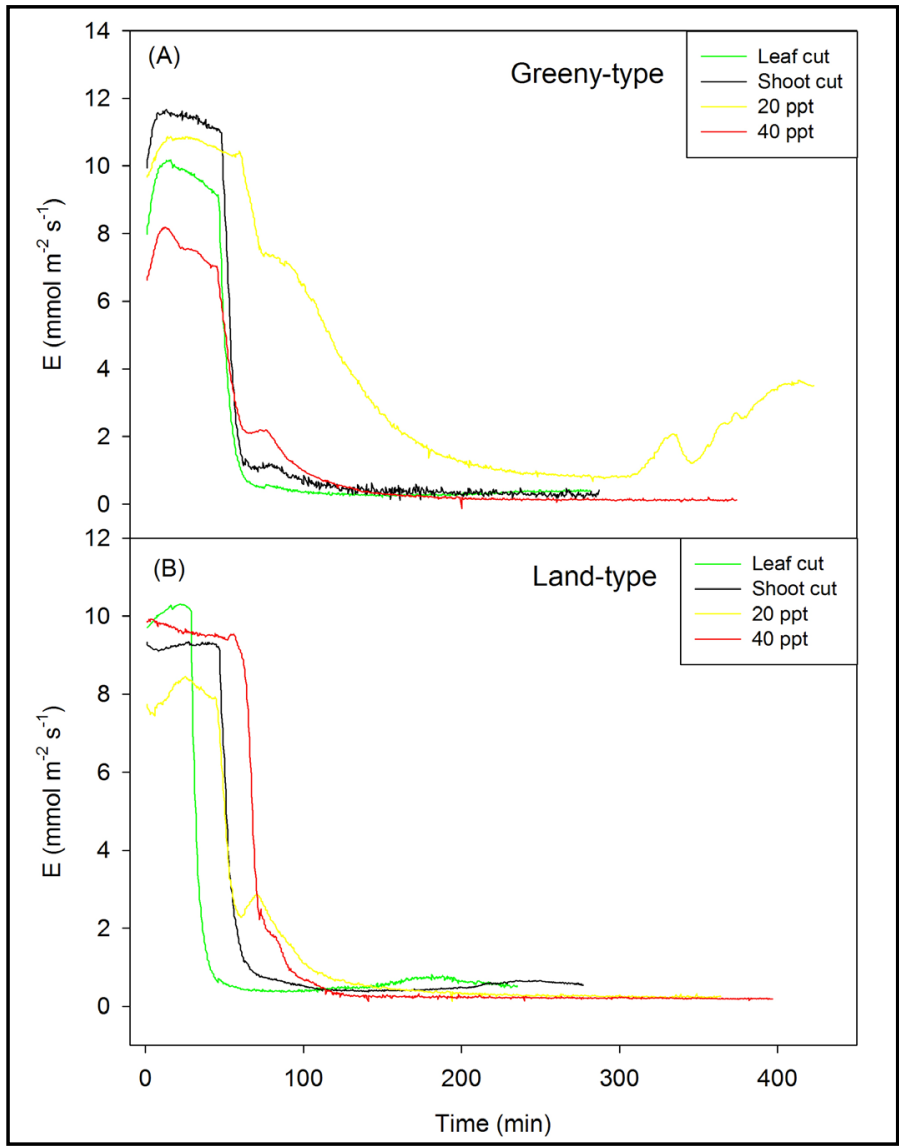

Figure 3. The response of the transpiration rate $(E)$ of two different $P$. australis clones to leaf cut, shoot cut, and administering 20 and $40 \mathrm{ppt}$ salt concentration for 4 hours.

in response to the flushing. However, similarly to $P_{\max }$, both $g_{s}$ and $E$ continued to decrease for the rest of the measuring time.

\section{Discussion}

An efficient regulation of osmotic stress is crucial for survival under salt-stress conditions. Plants exposed to salt for a longer period of time which fail to down-regulate their transpiration stream will inevitably uptake a higher amount of toxic solutes and thus accumulate ions in toxic concentrations inside the plant faster.

Salinity stress has similar effects to drought in the initial phase (osmotic phase), as high concentrations of salts in the soil make it harder for roots to extract water. Salts on the outside of roots have an immediate effect on cell turgor and associated metabolism, but toxic concentrations of salts take time to accumulate inside plants before they affect plant function. Therefore, the response exerted in the initial exclusion phase is particularly important in estimating the ability of a plant to cope with salt stress.

The short-time response to salt exposure of the two genetically distinct $P$. australis clones investigated in this study reveals efficient mechanisms to regulate osmotic stress through stomata closure and transpiration reduction. These responses have been previously associated to changes in the soil water potential, as they can also be measured in response to drought [11].

Similarities between plants' response to water limitation and to salt exposure have previously been documented [25]. Our approach of cutting the measuring leaf (and therefore inducing severe water stress) demonstrated a very fast response to reduced water availability, indicating efficient signaling pathways. The response was equally fast when the entire shoot was cut, as our plants were very young and the shoots were still short and thin. Nonetheless, the results indicate fast transport of water (or, in this case, lack of transport) from the roots to the leaves. 

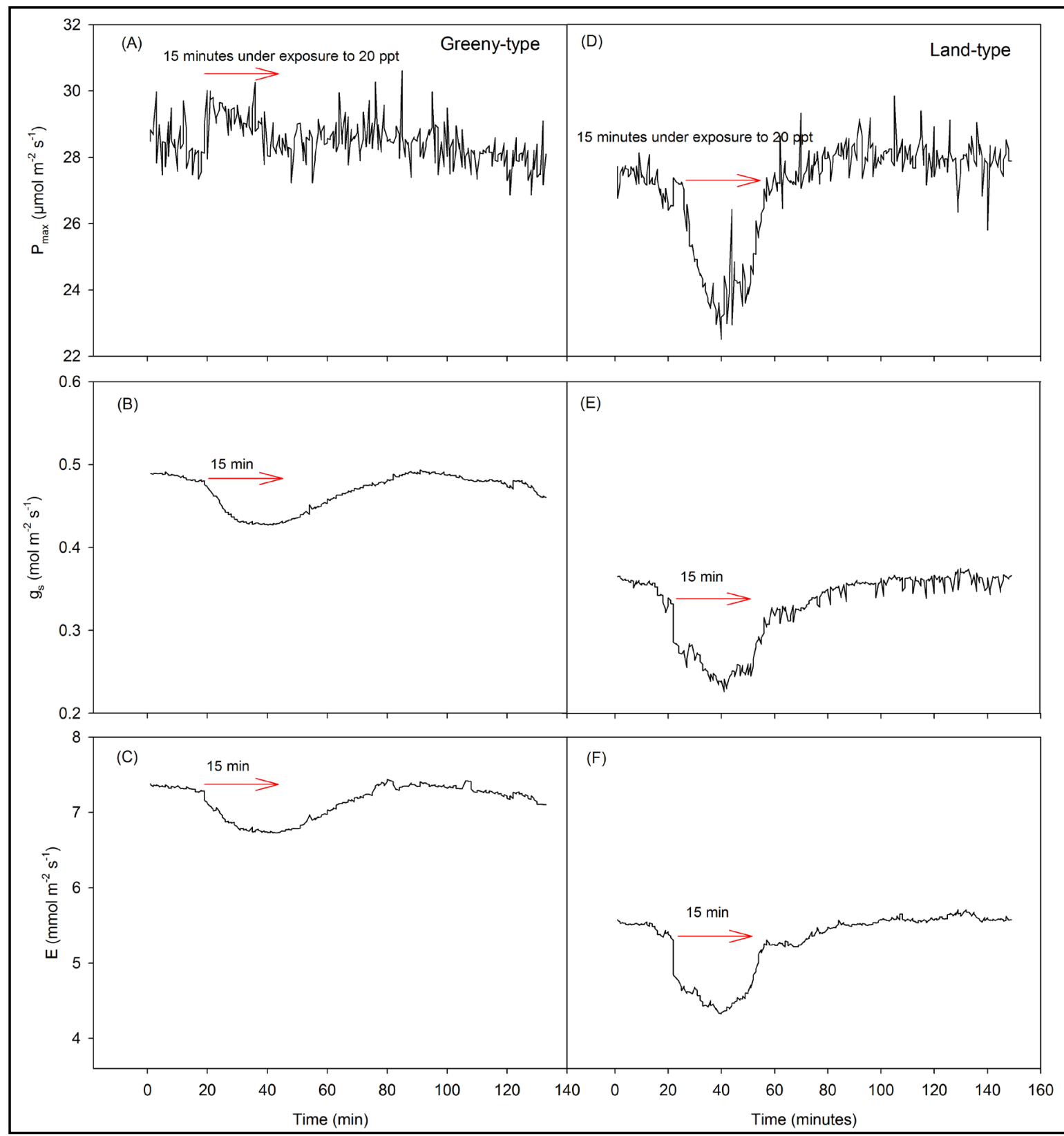

Figure 4. The response of the light-saturated rate of photosynthesis (A and D), stomata conductance (B and E) and transpiration rate $(\mathrm{C}$ and $\mathrm{F})$ of two different $P$. australis clones to administrating $20 \mathrm{ppt}$ salt concentration for 15 minutes. The first column shows the three parameters for the Greeny-type and the second for the Land-type. The salt solution was added after 20 minutes of stable conditions, as indicated by the red arrow.

Our study proved the hypothesis that the response time to sense and regulate osmotic stress varies between genotypes. The efficient osmotic response of the Greeny-type measured at 20 ppt suggests fast acclimation to changes in the water potential and a higher salinity tolerance level. The observed stabilization of $P_{\max }, g_{s}$ and $E$ of the Greeny-type after approximately 200 minutes of exposure to 20 ppt salt concentration shows a higher salinity tolerance of this clone, as well as its ability to function at this salt concentration. Moreover, the immediate recovery after rinsing the rhizosphere with fresh water indicates a high capacity to adjust to fluctuating soil water potential. It also suggests that no permanent damage occurred, the toxic ions inevitably up-taken being most likely isolated in the vacuoles. It is not the case of the Land-type, whose $P_{\max }, g_{s}$ and $E$ were totally impaired by the osmotic shock. 




Figure 5. The response of the light-saturated rate of photosynthesis (A and D), stomata conductance (B and E) and transpiration rate $(\mathrm{C}$ and $\mathrm{F})$ of two different $P$. australis clones to administrating $20 \mathrm{ppt}$ salt concentration for 70 minutes. The first column shows the three parameters for the Greeny-type and the second for the Land-type. The salt solution was added after 40 minutes of stable conditions, as indicated by the red arrow.

Previous results have shown that preventing $\mathrm{Na}^{+}$to enter the plant for as long as possible is essential for $P$. australis survival in saline conditions [19] [20]. Hence, initial exclusion seems a viable strategy for this species. Our results confirm the hypothesis that $P$. australis possesses mechanisms to prevent high amounts of toxic ions from entering the tissues. The immediate stomata closure observed for both clones exposed to salinity suggests that exclusion is the first attempt to protect against salinity stress.

However, the concentration of the salt solution plays a crucial role. As expected, our findings indicated that the response to osmotic shock was faster, at high salt concentrations. This may be due to hormones, such as ABA, which have been suggested to be involved in regulating osmotic stress [24]. The concentration of ABA seems to be directly related to the soil water potential in the root zone, which can be regarded as the "intensity" of the stress [26]. Yet, the results of this experiment indicated different responses of the two genotypes when exposed to the same salinity, as well as different salt tolerance levels. Complete inhibition was estimated when total stomata closure and no recovery were measured. Hence, the highest salinity tolerated by the Land-type was 
20 ppt, as also indicated by our previous results, while 40 ppt caused permanent damage for the Greeny-type. This result suggests differences in salinity tolerance comparable to the differences observed between different plant species [27]. Nonetheless, the stable values recorded shortly after the exposure of the Greeny-type to 40 ppt, which lasted for approximately $5-7$ minutes, indicate the potential of this clone to acclimate or at least survive for a limited period of time even at these high salinities. However, the premise for a potential acclimation would be a gradual increase of the salt concentration, as shown by Achenbach et al. [20], who exposed $P$. australis to progressively increased salinity and measured extremely high tolerance levels under these conditions. Another indicative of our findings is that the Greeny-type might recover even after exposure to high salinities (40 ppt), given that the exposure time is short enough. Hence, our results prove the hypothesis that the Greeny-type has a higher ability to acclimate to fluctuating salinity. This premise is further supported by the small increase of $g_{s}$ and $E$ (Figures 2(A) and 3(A) yellow curve) associated to draining the salt solution and rinsing the rhizosphere with fresh water, which indicates fast adjustment to the fluctuation in water level and thus, to changes in soil water potential.

We have also ascertained to which extent plants can regain functionality after different salt-stress exposure periods. Hence, for the tolerant clone, even an exposure of over four hours was followed by partial recovery, as soon as the stress was removed. For this clone we established that full functionality was recovered after 72 hours. In the case of the sensitive clone, the first signs of recovery appeared 24 hours after salt removal, but full functionality ( $P_{\max }, g_{s}$ and $E$ values comparable to the initial ones) was only measured as soon as a new leaf developed (sometimes more than a week). Furthermore, the measurements performed over 15 and 70 minutes salt exposure revealed total recovery for the tolerant clone, as opposed to the sensitive clone, which only fully recovered after the 15 minutes exposure and not after 70 minutes under salt stress.

Another important aspect of this experiment is the "recognition pattern" (plants dealing repeatedly with the same type of stress), as the 15 and 70 minutes measurements were performed on already salt-exposed plants, after one week of recovery. While at the first contact to 20 ppt salinity both clones reduced rather fast their physiological activity, the second osmotic shock, even if measured on a new, unexposed leaf, was much more reduced for the Land-type and practically non-existent for the Greeny-type, if we consider the same variation range. These results suggest acclimation to salinity stress conditions from both clones, but more efficient in the case of the Greeny-type. The response to repeated administration of salt treatment is extremely relevant, as also indicated by Doering et al. [28], since in the natural habitat of these clones, salinity pulses are frequent. Furthermore, periods of salt stress, alternating with periods of fresh water input are most likely the actual living conditions of these clones, rather than constant salinity stress.

It is interesting to note that even if the plants had been exposed to salinity before, and therefore the salinity stress did not strike so strongly, the exposure time did have a considerable impact. In the 15 minutes of salt stress, the tolerant clone (Greeny-type) was hardly affected by the change in soil water potential, whereas for the sensitive Land-type, the inhibition of $P_{\max }, g_{s}$ and $E$ was considerably higher even in this short period of time.

The 70 minutes exposure, on the other hand, was enough to provoke a stress response also on the tolerant clone. Nonetheless, the recovery after rinsing the root zone with fresh water was immediate, and to the exact same values as before disturbance for the Greeny-type. More importantly, a higher transpiration rate and stomata conductance were measured after the stress was removed, suggesting a compensation mechanism that aims to reduce the concentration of the already up-taken ions in the tissues.

The most surprising result is the continuous decline of $P_{\max }, g_{s}$ and $E$ of the Land-type, even after the salt solution had been removed. These results suggest that there might be ionic stress despite the relatively short exposure. This type of stress craves more energy from the plant, since it generates more complex defensive mechanisms [29]. Entering the ionic stress phase so fast also implies that the Land-type has less efficient selective channels that can prevent toxic ions from entering the cells. Hence, there are genotype-dependent features that regulate salinity stress and therefore the response of genetically distinct clones to salt exposure may vary greatly.

The results of this study support the hypothesis that differences in salinity tolerance of the two genetically distinct $P$. australis clones are due to genotype-predetermined tolerance levels and may be associated with distinct ecophysiological traits that are responsible for regulating the uptake in response to changes in the soil water potential.

\section{Conclusions}

The immediate response of $P$. australis to salt exposure is a down-regulation of water uptake through reduced 
stomata conductance and transpiration rate. The response is dependent both on the salt concentration and on the exposure time, as distinct clones have different, most likely genotype-related, salinity tolerance levels.

$P$. australis possesses efficient physiological mechanisms to regulate the osmotic stress. Hence, as various physiological traits can adjust to changing soil salinity, they are of major importance in the osmotic phase of salt exposure. An immediate regulation of the stomata conductance and of the transpiration stream, both downwards (at low water potential) and upwards (at high water potential) seems to be an essential mechanism for coping with high soil salinities. Adjusting the water uptake in response to the salinity in the root zone allows salt-tolerant clones to take advantage of freshwater pulses and thus function better under fluctuating salt stress. Furthermore, this feature may contribute to faster establishment and better growth in brackish wetland areas and may constitute a major advantage in becoming dominant in habitats with fluctuating salinity regimes. Thus, the distribution of the Greeny-type in the salt marshes of the Mississippi River Delta is likely to increase in the disfavor of the Land-type. The dynamics of distinct $P$. australis populations in the area are nonetheless very complex.

\section{Acknowledgements}

We thank the Danish Council for Independent Research-Natural Sciences for funding this research and the Carlsberg Foundation for the Li-Cor Equipment. We also thank Dr. Carla Lambertini from Aarhus University and Dr. Irving Mendelssohn from Louisiana State University, who helped with sampling in the Mississippi Delta.

\section{References}

[1] Brix, H. (1999) Genetic Diversity, Ecophysiology and Growth Dynamics of Reed (Phragmites australis)—Introduction. Aquatic Botany, 64, 179-184.

[2] Lambertini, C., Gustafsson, M.H.G., Frydenberg, J., Lissner, J., Speranza, M. and Brix, H. (2006) A Phylogeographic Study of the Cosmopolitan Genus Phragmites (Poaceae) based on AFLPs. Plant Systematics and Evolution, 258, 161182. http://dx.doi.org/10.1007/s00606-006-0412-2

[3] Achenbach, L., Lambertini, C. and Brix, H. (2012) Phenotypic Traits of Phragmites australis Clones Are Not Related to Ploidy Level and Distribution Range. AoB Plants, 2012, Article ID: pls017. http://dx.doi.org/10.1093/aobpla/pls017

[4] Clevering, O.A. and Lissner, J. (2000) Taxonomy, Chromosome Numbers, Clonal Diversity and Population Dynamics of Phragmites australis. Aquatic Botany, 66, 249-250. http://dx.doi.org/10.1016/S0304-3770(00)00094-2

[5] Hansen, D.L., Lambertini, C., Jampeetong, A. and Brix, H. (2007) Clone-Specific Differences in Phragmites australis: Effects of Ploidy Level and Geographic Origin. Aquatic Botany, 86, 269-279. http://dx.doi.org/10.1016/j.aquabot.2006.11.005

[6] Kuhl, H., Koppitz, H., Rolletschek, H. and Kohl, J.G. (1999) Clone-Specific Differences in a Phragmites australis Stand I. Morphology, Genetics and Site Description. Aquatic Botany, 64, 235-246. http://dx.doi.org/10.1016/S0304-3770(99)00053-4

[7] Pauca-Comanescu, M., Clevering, O.A., Hanganu, J. and Gridin, M. (1999) Phenotypic Differences among Ploidy Levels of Phragmites australis growing in Romania. Aquatic Botany, 64, 223-234. http://dx.doi.org/10.1016/S0304-3770(99)00052-2

[8] Gorai, M., Ennajeh, M., Khemira, H. and Neffati, M. (2010) Combined Effect of NaCl-Salinity and Hypoxia on Growth, Photosynthesis, Water Relations and Solute Accumulation in Phragmites australis Plants. Flora, 205, 462470. http://dx.doi.org/10.1016/j.flora.2009.12.021

[9] Lessmann, J.M., Brix, H., Bauer, V., Clevering, O.A. and Comin, F.A. (2001) Effect of Climatic Gradients on the Photosynthetic Responses of Four Phragmites australis Populations. Aquatic Botany, 69, 109-126. http://dx.doi.org/10.1016/S0304-3770(01)00133-4

[10] Lissner, J., Schierup, H.H., Comin, F.A. and Astorga, V. (1999) Effect of Climate on the Salt Tolerance of two Phragmites australis Populations. I. Growth, Inorganic Solutes, Nitrogen Relations and Osmoregulation. Aquatic Botany, 64, 317-333. http://dx.doi.org/10.1016/S0304-3770(99)00060-1

[11] Pagter, M., Bragato, C. and Brix, H. (2005) Tolerance and Physiological Responses of Phragmites australis to Water Deficit. Aquatic Botany, 81, 285-299. http://dx.doi.org/10.1016/j.aquabot.2005.01.002

[12] Pagter, M., Bragato, C., Malagoli, M. and Brix, H. (2009) Osmotic and Ionic Effects of $\mathrm{NaCl}$ and $\mathrm{Na}_{2} \mathrm{SO}_{4} \mathrm{Salinity} \mathrm{on}$ Phragmites australis. Aquatic Botany, 90, 43-51. http://dx.doi.org/10.1016/j.aquabot.2008.05.005

[13] Vasquez, E.A., Glenn, E.P., Guntenspergen, G.R., Brown, J.J. and Nelson, S.G. (2006) Salt Tolerance and Osmotic Adjustment of Spartina alterniflora (Poaceae) and the Invasive M Haplotype of Phragmites australis (Poaceae) along 
a Salinity Gradient. American Journal of Botany, 93, 1784-1790. http://dx.doi.org/10.3732/ajb.93.12.1784

[14] Meadows, R.E. and Saltonstall, K. (2007) Distribution of Native and Introduced Phragmites australis in Freshwater and Oligohaline Tidal Marshes of the Delmarva Peninsula and Southern New Jersey. Journal of the Torrey Botanical Society, 134, 99-107. http://dx.doi.org/10.3159/1095-5674(2007)134[99:DONAIP]2.0.CO;2

[15] Saltonstall, K. (2002) Cryptic Invasion by a Non-Native Genotype of the Common Reed, Phragmites australis, into North America. Proceedings of the National Academy of Sciences of the United States of America, 99, 2445-2449. http://dx.doi.org/10.1073/pnas.032477999

[16] Zedler, J. B. and Kercher, S. (2004) Causes and Consequences of Invasive Plants in Wetlands: Opportunities, Opportunists, and Outcomes. Critical Reviews in Plant Sciences, 23, 431-452. http://dx.doi.org/10.1080/07352680490514673

[17] Hauber, D.P., Saltonstall, K., White, D.A. and Hood, C.S. (2011) Genetic Variation in the Common Reed, Phragmites australis, in the Mississippi River Delta Marshes: Evidence for Multiple Introductions. Estuaries and Coasts, 34, 851862. http://dx.doi.org/10.1007/s12237-011-9391-9

[18] Lambertini, C., Mendelssohn, I.A., Gustafsson, M.H.G., Olesen, B., Riis, T., Sorrell, B.K. and Brix, H. (2012) Tracing the Origin of Gulf Coast Phragmites (Poaceae): A Story of Long-Distance Dispersal and Hybridization. American Journal of Botany, 99, 538-551. http://dx.doi.org/10.3732/ajb.1100396

[19] Achenbach, L. and Brix, H. (2013) Can Differences in Salinity Tolerance Explain the Distribution of Four Genetically Distinct Lineages of Phragmites australis in the Mississippi River Delta. Hydrobiologia. http://dx.doi.org/10.1007/s10750-013-1601-y

[20] Achenbach, L., Eller, F., Nguyen, L.X. and Brix, H. (2013) Differences in Salinity Tolerance of Genetically Distinct Phragmites australis Clones. AoB Plants, 5, Article ID: plt019. http://dx.doi.org/10.1093/aobpla/plt019

[21] Gao, L., Tang, S., Zhuge, L., Nie, M., Zhu, Z., Li, B. and Yang, J. (2012) Spatial Genetic Structure in Natural Populations of Phragmites australis in a Mosaic of Saline Habitats in the Yellow River Delta, China. PLoS ONE, 7, Article ID: e43334. http://dx.doi.org/10.1371/journal.pone.0043334

[22] Gorai, M., Ennajeh, M., Khemira, H. and Neffati, M. (2011) Influence of NaCl-Salinity on Growth, Photosynthesis, Water Relations and Solute Accumulation in Phragmites australis. Acta Physiologiae Plantarum, 33, 963-971. http://dx.doi.org/10.1007/s11738-010-0628-1

[23] Hanganu, J., Mihail, G. and Coops, H. (1999) Responses of Ecotypes of Phragmites australis to Increased Seawater Influence: A Field Study in the Danube Delta, Romania. Aquatic Botany, 64, 351-358. http://dx.doi.org/10.1016/S0304-3770(99)00062-5

[24] Munns, R. and Tester, M. (2008) Mechanisms of Salinity Tolerance. Annual Review of Plant Biology, 59, $651-681$. http://dx.doi.org/10.1146/annurev.arplant.59.032607.092911

[25] Munns, R. (2002) Comparative Physiology of Salt and Water Stress. Plant, Cell \& Environment, 25, 239-250. http://dx.doi.org/10.1046/j.0016-8025.2001.00808.x

[26] Zhu, J.K. (2002) Salt and Drought Stress Signal Transduction in Plants. Annual Reviews Plant Biology, 53, $247-273$. http://dx.doi.org/10.1146/annurev.arplant.53.091401.143329

[27] Mühling, K.H. and Läuchli, A. (2002) Effect of Salt Stress on Growth and Cation Compartmentation in Leaves of Two Plant Species Differing in Salt Tolerance. Journal of Plant Physiology, 159, 137-146. http://dx.doi.org/10.1078/0176-1617-00701

[28] Doering, P.H., Chamberlain, R.H. and McMunigal, J.M. (2001) Effects of Simulated Saltwater Intrusions on the Growth and Survival of Wild Celery, Vallisneria americana, from the Caloosahatchee Estuary (South Florida). Estuaries, 24, 894-903. http://dx.doi.org/10.2307/1353180

[29] Greenway, H. and Munns, R. (1980) Mechanisms of Salt Tolerance in Non-Halophytes. Annual Review of Plant Physiology and Plant Molecular Biology, 31, 149-190. http://dx.doi.org/10.1146/annurev.pp.31.060180.001053 